\title{
LOS DOCUMENTALES Y NOTICIARIOS COMO TEXTO DE APERTURA PARA PENSAR LA EDUCACIÓN ESTÉTICO-POLÍTICA
}

\section{The documentaries and newsreels as an open text for thinking about the aesthetical and political education}

\section{Eulàlia Collelldemont Pujadas* y Josep Casanovas Prat ${ }^{\S}$}

Fecha de recepción: 24/05/2016 • Fecha de aceptación: 23/10/2016

Resumen. El uso de documentales y noticiarios como fuente de estudio y divulgación de la memoria educativa nos permite acceder a las visiones promovidas desde los diferentes grupos ideológicos. Esta posibilidad es especialmente manifiesta en los noticiarios y documentales producidos durante la Guerra Civil Española. Momento en el que la forma estética y los contenidos narrativos se fusionan dando voz a los imaginarios propuestos desde las diferentes formaciones políticas. Para posteriores estudios detallados, se ha considerado necesario la recopilación y difusión de este patrimonio histórico-educativo.

Palabras clave: Propaganda pedagógica; Ideologías de la educación; Patrimonio audiovisual.

Abstract. The use of documentaries and newsreels as a source for the study and dissemination of the educational memory gives us access to the visions promoted by different ideological groups. The nature and differences in perspective in the newsreels and documentaries produced during the Spanish Civil War are especially notorious, providing us with a glimpse of a time when novel aesthetic and narrative content came together to facilitate the the creation of collective imaginaries as proposed by the different political parties. Studies of this historical period have necessarily resorted to summaries and campaigns of this historical-educational heritage.

Keywords: Educational propaganda; Ideologies of the education; Film heritage.

\footnotetext{
* Departament de Pedagogia. Facultat d'Educación, Ciències Humames i Traducció. Universitat de Vic - Universitat Central de Catalunya. C. Sagrada Família, 7. 08500 Vic. España. eulalia@uvic.cat $\S$ Departament de Pedagogia. Facultat d'Educación, Ciències Humames i Traducció. Universitat de Vic - Universitat Central de Catalunya. C. Sagrada Família, 7.08500 Vic. España. josep.casanovas@uvic.cat
}

Cómo citar este artículo: Collelldemont Pujadas, Eulàlia y Casanovas Prat, Josep. «Los documentales y noticiarios como texto de apertura para pensar la educación estético-política», Historia y Memoria de la Educación, 5 (2017): 467-487. 
En esta ocasión, y en coherencia con el tema del monográfico, proponemos el estudio de textos audiovisuales que en forma de documentales y noticiarios fueron producidos durante la guerra civil española. Mediatizados con una profunda carga simbólica a tenor de una propaganda que incitaba a la acción, esas producciones se revistieron de una forma textual que, sin lugar a dudas, permite al historiador de hoy conocer más sobre las concreciones que las diferentes opciones políticas implicaban. Con una economía de guerra que limitaba las posibilidades de expansión de la narración, por lo que habían de ser breves y concisas, aquello que se observa en esta tipología de producciones audiovisuales es una síntesis de lo prioritario.

Con la voluntad de documentar parte de la realidad y con el fin de transformar las otras realidades, las producciones fílmicas del período que nos ocupa (1936-1939) no hacían claras distinciones entre los noticiarios y los documentales. Habitualmente, la duración tanto de los documentales como de los noticiarios era desigual: con independencia de si eran documentales o noticiarios, estos podían durar entre 2 y 30 minutos. Las dos formas de representación de la realidad se asemejaban en los temas de desarrollo. Estos pivotaban sobre un núcleo temático, que podía ser el frente, la retaguardia, manifestaciones o actos políticos, breves apuntes del exterior. No sería hasta la década de los cuarenta cuando los noticiarios abarcarían una amplitud temática mayor. Así mismo documentales y noticiarios eran parecidos en la estructura temporal, iniciándose con imágenes de la realidad, desenvolviendo el tema a partir de secuencias entrelazadas y con un final que contenía la propuesta ideológica. Las voces incorporadas - cuando existían- presentaban también tonos y ritmos parecidos. La mecánica de la producción era también la misma. Por lo tanto, no es de extrañar que, incluso en determinadas ocasiones, algunos fragmentos fueran utilizados indistintamente y de manera repetida por noticiarios y documentales.

En este contexto de representación gráfica que bajo una economía productiva de guerra tenía que priorizar los temas a presentar, destaca que en el catálogo realizado por Alfonso del Amo García ${ }^{1}$ hay un número claramente significativo de referencias a la atención -protección y educación- de la infancia. De entre las mismas, pueden visionarse en la Filmoteca Española y la Filmoteca de Cataluña los siguientes títulos:

\footnotetext{
${ }^{1}$ Alfonso del Amo García, Catálogo General del cine de la Guerra Civil (Madrid: Cátedra-Filmoteca Española, 1996).
} 


\section{Documentales y noticiarios producidos en España}

\begin{tabular}{|c|c|c|c|c|c|c|}
\hline Fecha & Título & $\begin{array}{l}\text { Dura- } \\
\text { ción }\end{array}$ & Créditos & Filmoteca & Tipología & Ideología $^{2}$ \\
\hline 1936 & $\begin{array}{l}\text { Homenaje a la } \\
\text { bandera } \\
\text { nacional }\end{array}$ & $12^{\prime}$ & $\begin{array}{l}\text { Prod.: Films Patria - } \\
\text { Lisboa Filme } \\
\text { Dir.: - }\end{array}$ & $\begin{array}{l}\text { Filmoteca } \\
\text { Española }\end{array}$ & Documental & Franquista \\
\hline 1936 & $\begin{array}{l}\text { Oviedo, la } \\
\text { mártir }\end{array}$ & $13^{\prime}$ & $\begin{array}{l}\text { Prod.: Patria Films - } \\
\text { Lisboa Filme }\end{array}$ & $\begin{array}{l}\text { Filmoteca } \\
\text { Española }\end{array}$ & Documental & Franquista \\
\hline 1936 & $\begin{array}{l}\text { (18 de julio) } \\
\text { n. 2- Madrid }\end{array}$ & $15^{\prime}$ & $\begin{array}{l}\text { Prod.: Izquierda } \\
\text { Republicana } \\
\text { Dir.: Arturo Ruiz-Castillo }\end{array}$ & $\begin{array}{l}\text { Filmoteca } \\
\text { Española }\end{array}$ & Documental & $\begin{array}{l}\text { Gubernamental- } \\
\text { republicana }\end{array}$ \\
\hline 1936 & $\begin{array}{l}\text { El instituto } \\
\text { regional } \\
\text { agropecuario } \\
\end{array}$ & $10^{\prime}$ & $\begin{array}{l}\text { Prod.: Federación } \\
\text { regional de campesinos y } \\
\text { alimentación - CNT }\end{array}$ & $\begin{array}{l}\text { Filmoteca } \\
\text { Española }\end{array}$ & Documental & Anarquista \\
\hline 1936 & $\begin{array}{l}\text { Nosotros somos } \\
\text { así }\end{array}$ & $29^{\prime} 30^{\prime \prime}$ & $\begin{array}{l}\text { Prod.: S. I. E. Films } \\
\text { Dir.: Valentín R. González }\end{array}$ & $\begin{array}{l}\text { Filmoteca } \\
\text { de } \\
\text { Catalunya } \\
\end{array}$ & $\begin{array}{l}\text { Documental - } \\
\text { Ficción }\end{array}$ & Anarquista \\
\hline 1936 & $\begin{array}{l}\text { Reportaje del } \\
\text { Movimiento } \\
\text { Revolucionario } \\
\text { en Barcelona } \\
\end{array}$ & $22^{\prime}$ & $\begin{array}{l}\text { Prod.: CNT - FAI (Oficina } \\
\text { de Información y } \\
\text { Propaganda) } \\
\text { Dir:: Mateo Santos } \\
\end{array}$ & $\begin{array}{l}\text { Filmoteca } \\
\text { Española }\end{array}$ & Documental & Anarquista \\
\hline 1936 & $\begin{array}{l}\text { Solidaridad del } \\
\text { pueblo hacia las } \\
\text { víctimas del } \\
\text { Franquismo } \\
\end{array}$ & $11^{\prime}$ & $\begin{array}{l}\text { Prod.: CNT-FAI } \\
\text { Dir.: Sie Films }\end{array}$ & $\begin{array}{l}\text { Filmoteca } \\
\text { Española }\end{array}$ & Documental & Anarquista \\
\hline 1937 & $\begin{array}{l}\text { Franco en } \\
\text { Salamanca I - A } \\
\text { los niños } \\
\text { alemanes }\end{array}$ & - & $\begin{array}{l}\text { Prod.: - } \\
\text { Dir:: - }\end{array}$ & $\begin{array}{l}\text { Filmoteca } \\
\text { Española }\end{array}$ & Documental & Franquista \\
\hline 1937 & $\begin{array}{l}\text { Sevilla } \\
\text { rescatado }\end{array}$ & $11^{\prime}$ & $\begin{array}{l}\text { Prod.: Cifesa } \\
\text { Dir:: Alfredo Fraile }\end{array}$ & $\begin{array}{l}\text { Filmoteca } \\
\text { Española }\end{array}$ & Documental & Franquista \\
\hline 1937 & $\begin{array}{l}\text { Reconstruyendo } \\
\text { España. N. } 1\end{array}$ & $10^{\prime}$ & $\begin{array}{l}\text { Prod.: CIFESA } \\
\text { Dir:: Alfredo Fraile }\end{array}$ & $\begin{array}{l}\text { Filmoteca } \\
\text { Española }\end{array}$ & Documental & Franquista \\
\hline 1937 & $\begin{array}{l}\text { Reconstruyendo } \\
\text { España. N. } 2\end{array}$ & $10^{\prime}$ & $\begin{array}{l}\text { Prod.: CIFESA } \\
\text { Dir:: Alfredo Fraile }\end{array}$ & $\begin{array}{l}\text { Filmoteca } \\
\text { Española }\end{array}$ & Documental & Franquista \\
\hline 1937 & $\begin{array}{l}\text { El camino de la } \\
\text { victoria }\end{array}$ & $21^{\prime} 30^{\prime \prime}$ & $\begin{array}{l}\text { Prod.: Partido Comunista } \\
\text { de España } \\
\text { Dir.: Antonio del Amo }\end{array}$ & $\begin{array}{l}\text { Filmoteca } \\
\text { Española }\end{array}$ & Documental & Comunista \\
\hline
\end{tabular}

2 Para un estudio sobre las ideologías y análisis de las producciones de las distintas productoras ver Magí Crusells, «El cine durante la Guerra Civil Española», Comunicación y Sociedad. XI (2), (1998): 123-152, consultado el 24 de mayo de 2016, URL: http://www.unav.es/fcom/communication-society/es/articulo.php?art_id=145 


\begin{tabular}{|c|c|c|c|c|c|c|}
\hline Fecha & Título & $\begin{array}{l}\text { Dura- } \\
\text { ción }\end{array}$ & Créditos & Filmoteca & Tipología & Ideología $^{2}$ \\
\hline 1937 & $\begin{array}{l}\text { Un periódico } \\
\text { mural }\end{array}$ & 6'30" & $\begin{array}{l}\text { Prod.: Ediciones } \\
\text { Antifascistas Films } \\
\text { Dir.: Manuel Ordóñez }\end{array}$ & $\begin{array}{l}\text { Filmoteca } \\
\text { Española }\end{array}$ & Documental & Comunista \\
\hline 1937 & $\begin{array}{l}\text { [Instituto para } \\
\text { obreros] }\end{array}$ & $5^{\prime} 58^{\prime \prime}$ & $\begin{array}{l}\text { Prod.: Film Popular } \\
\text { Dir.: - }\end{array}$ & $\begin{array}{l}\text { Filmoteca } \\
\text { Española }\end{array}$ & Documental & $\begin{array}{l}\text { Gubernamental- } \\
\text { republicana }\end{array}$ \\
\hline 1937 & $\begin{array}{l}\text { Concentración } \\
\text { Juventudes } \\
\text { Antifascistas }\end{array}$ & $4^{\prime}$ & $\begin{array}{l}\text { Prod.: Film Popular } \\
\text { Dir.: - }\end{array}$ & $\begin{array}{l}\text { Filmoteca } \\
\text { Española }\end{array}$ & Documental & $\begin{array}{l}\text { Gubernamental- } \\
\text { republicana }\end{array}$ \\
\hline 1937 & $\begin{array}{l}\text { España al día. } \\
\text { Avicultura. } \\
\text { Valencia. } \\
\text { Granja-Escuela }\end{array}$ & $9^{\prime}$ & $\begin{array}{l}\text { Prod.: Film Popular } \\
\text { Dir.: - }\end{array}$ & $\begin{array}{l}\text { Filmoteca } \\
\text { de Valencia }\end{array}$ & $\begin{array}{l}\text { Documental - } \\
\text { noticiario }\end{array}$ & $\begin{array}{l}\text { Gubernamental- } \\
\text { republicana }\end{array}$ \\
\hline 1937 & $\begin{array}{l}\text { España al día. } \\
\text { Fragmentos. } \\
\text { Protección a la } \\
\text { escuela de } \\
\text { retaguarda }\end{array}$ & $10^{\prime}$ & $\begin{array}{l}\text { Prod.: Laya Films } \\
\text { Dir.: - }\end{array}$ & $\begin{array}{l}\text { Filmoteca } \\
\text { Española }\end{array}$ & $\begin{array}{l}\text { Documental - } \\
\text { noticiario }\end{array}$ & $\begin{array}{l}\text { Gubernamental- } \\
\text { republicana }\end{array}$ \\
\hline 1937 & $\begin{array}{l}\text { España al día } \\
\text { (Vascongadas) }\end{array}$ & - & $\begin{array}{l}\text { Prod.: Film Popular - } \\
\text { Laya Films } \\
\text { Dir.: - }\end{array}$ & $\begin{array}{l}\text { Filmoteca } \\
\text { Española }\end{array}$ & $\begin{array}{l}\text { Documental - } \\
\text { noticiario }\end{array}$ & $\begin{array}{l}\text { Gubernamental- } \\
\text { republicana }\end{array}$ \\
\hline 1937 & $\begin{array}{l}\text { España al día - } \\
\text { Nouvelles } \\
\text { d'Espagne: } \\
\text { Education. } \\
\text { Barcelone }\end{array}$ & - & $\begin{array}{l}\text { Prod.: Film Popular - } \\
\text { Laya Films } \\
\text { Dir.: - }\end{array}$ & $\begin{array}{l}\text { Filmoteca } \\
\text { Española }\end{array}$ & $\begin{array}{l}\text { Documental - } \\
\text { noticiario }\end{array}$ & $\begin{array}{l}\text { Gubernamental- } \\
\text { republicana }\end{array}$ \\
\hline 1937 & $\begin{array}{l}\text { España al día } \\
\text { (Barcelona. } \\
\text { En el Ministerio } \\
\text { de Instrucción } \\
\text { Pública) }\end{array}$ & - & $\begin{array}{l}\text { Prod.: Film Popular - } \\
\text { Laya Films } \\
\text { Dir.: - }\end{array}$ & $\begin{array}{l}\text { Filmoteca } \\
\text { Española }\end{array}$ & $\begin{array}{l}\text { Documental - } \\
\text { noticiario }\end{array}$ & $\begin{array}{l}\text { Gubernamental- } \\
\text { republicana }\end{array}$ \\
\hline 1937 & $\begin{array}{l}\text { España al día } \\
\text { (Menjadors } \\
\text { infantils) } \\
\end{array}$ & - & $\begin{array}{l}\text { Prod.: Film Popular - } \\
\text { Laya Films } \\
\text { Dir:: - } \\
\end{array}$ & $\begin{array}{l}\text { Filmoteca } \\
\text { Española }\end{array}$ & $\begin{array}{l}\text { Documental - } \\
\text { noticiario }\end{array}$ & $\begin{array}{l}\text { Gubernamental- } \\
\text { republicana }\end{array}$ \\
\hline 1937 & $\begin{array}{l}\text { España al día } \\
\text { (Madrid } \\
\text { Evacuaciones) }\end{array}$ & - & $\begin{array}{l}\text { Prod.: Film Popular - } \\
\text { Laya Films } \\
\text { Dir.: - }\end{array}$ & $\begin{array}{l}\text { Filmoteca } \\
\text { Española }\end{array}$ & $\begin{array}{l}\text { Documental - } \\
\text { noticiario }\end{array}$ & $\begin{array}{l}\text { Gubernamental- } \\
\text { republicana }\end{array}$ \\
\hline 1937 & $\begin{array}{l}\text { España al día } \\
\text { (Ofrena als } \\
\text { infants) }\end{array}$ & - & $\begin{array}{l}\text { Prod.: Film Popular - } \\
\text { Laya Films } \\
\text { Dir.: - }\end{array}$ & $\begin{array}{l}\text { Filmoteca } \\
\text { Española }\end{array}$ & $\begin{array}{l}\text { Documental - } \\
\text { noticiario }\end{array}$ & $\begin{array}{l}\text { Gubernamental- } \\
\text { republicana }\end{array}$ \\
\hline
\end{tabular}




\begin{tabular}{|c|c|c|c|c|c|c|}
\hline Fecha & Título & $\begin{array}{l}\text { Dura- } \\
\text { ción }\end{array}$ & Créditos & Filmoteca & Tipología & Ideología $^{2}$ \\
\hline 1937 & $\begin{array}{l}\text { España al día } \\
\text { (Retaguardia. } \\
\text { Barcelona en la } \\
\text { escuela del } \\
\text { preaprendizaje) }\end{array}$ & - & $\begin{array}{l}\text { Prod.: Film Popular - } \\
\text { Laya Films } \\
\text { Dir:: - }\end{array}$ & $\begin{array}{l}\text { Filmoteca } \\
\text { Española }\end{array}$ & $\begin{array}{l}\text { Documental - } \\
\text { noticiario }\end{array}$ & $\begin{array}{l}\text { Gubernamental- } \\
\text { republicana }\end{array}$ \\
\hline 1937 & Aragón 1937 & $16^{\prime}$ & $\begin{array}{l}\text { Prod.: Laya Films } \\
\text { Dir.: - }\end{array}$ & $\begin{array}{l}\text { Filmoteca } \\
\text { de } \\
\text { Catalunya }\end{array}$ & Documental & $\begin{array}{l}\text { Gubernamental- } \\
\text { republicana }\end{array}$ \\
\hline 1937 & Espagne 1936 & $35^{\prime}$ & $\begin{array}{l}\text { Prod.: Subsecretaría de } \\
\text { Propaganda del Gobierno } \\
\text { de la República } \\
\text { Dir.: Jean Paul Le Chanois }\end{array}$ & $\begin{array}{l}\text { Filmoteca } \\
\text { Española }\end{array}$ & Documental & $\begin{array}{l}\text { Gubernamental- } \\
\text { republicana }\end{array}$ \\
\hline 1937 & España vieja & - & $\begin{array}{l}\text { Prod. Milicias de la } \\
\text { Cultura (Ministerio de } \\
\text { Instrucción Pública y } \\
\text { Sanidad) }\end{array}$ & $\begin{array}{l}\text { Filmoteca } \\
\text { Española }\end{array}$ & Documental & $\begin{array}{l}\text { Gubernamental- } \\
\text { republicana }\end{array}$ \\
\hline 1937 & $\begin{array}{l}\text { Noticiario de } \\
\text { Laya Films. } \\
\text { N.1. } \\
\end{array}$ & - & $\begin{array}{l}\text { Prod.: Laya Films } \\
\text { Dir:: - }\end{array}$ & $\begin{array}{l}\text { Filmoteca } \\
\text { Española }\end{array}$ & \begin{tabular}{|l|} 
Documental - \\
noticiario
\end{tabular} & $\begin{array}{l}\text { Gubernamental- } \\
\text { republicana }\end{array}$ \\
\hline 1937 & $\begin{array}{l}\text { Noticiario de } \\
\text { Laya Films. N.2 }\end{array}$ & - & $\begin{array}{l}\text { Prod.: Laya Films } \\
\text { Dir.: - }\end{array}$ & $\begin{array}{l}\text { Filmoteca } \\
\text { Española } \\
\end{array}$ & \begin{tabular}{|l|}
$\begin{array}{l}\text { Documental - } \\
\text { noticiario }\end{array}$ \\
\end{tabular} & $\begin{array}{l}\text { Gubernamental- } \\
\text { republicana }\end{array}$ \\
\hline 1937 & $\begin{array}{l}\text { Noticiario de } \\
\text { Laya Films. N.3 }\end{array}$ & $10^{\prime}$ & $\begin{array}{l}\text { Prod.: Laya Films } \\
\text { Dir.: - }\end{array}$ & $\begin{array}{l}\text { Filmoteca } \\
\text { Española }\end{array}$ & $\begin{array}{l}\text { Documental - } \\
\text { noticiario }\end{array}$ & $\begin{array}{l}\text { Gubernamental- } \\
\text { republicana }\end{array}$ \\
\hline 1937 & \begin{tabular}{|l} 
Noticiario de \\
Laya Films. N.4
\end{tabular} & $13^{\prime}$ & $\begin{array}{l}\text { Prod.: Laya Films } \\
\text { Dir.: - }\end{array}$ & $\begin{array}{l}\text { Filmoteca } \\
\text { Española }\end{array}$ & $\begin{array}{l}\text { Documental - } \\
\text { noticiario }\end{array}$ & $\begin{array}{l}\text { Gubernamental- } \\
\text { republicana }\end{array}$ \\
\hline 1937 & $\begin{array}{l}\text { Laya Films } \\
\text { (Noticiari } \\
\text { cinematogràfic } \\
\text { català, 1937) } \\
\end{array}$ & 42 & $\begin{array}{l}\text { Prod.: Laya Films } \\
\text { Dir.: - }\end{array}$ & & $\begin{array}{l}\text { Documental - } \\
\text { noticiario }\end{array}$ & $\begin{array}{l}\text { Gubernamental- } \\
\text { republicana }\end{array}$ \\
\hline 1937 & $\begin{array}{l}\text { [Albergues } \\
\text { niños. } \\
\text { Educación } \\
\text { física jóvenes] }\end{array}$ & $57^{\prime \prime}$ & $\begin{array}{l}\text { Prod.: - } \\
\text { Dir:: - }\end{array}$ & $\begin{array}{l}\text { Filmoteca } \\
\text { Española }\end{array}$ & Documental & Anarquista \\
\hline 1937 & $\begin{array}{l}\text { El Frente y la } \\
\text { Retaguardia }\end{array}$ & $22^{\prime}$ & $\begin{array}{l}\text { Prod.: SIE } \\
\text { Dir.: Joaquín Giner }\end{array}$ & $\begin{array}{l}\text { Filmoteca } \\
\text { Española }\end{array}$ & Documental & Anarquista \\
\hline 1938 & $\begin{array}{l}\text { Amanecer sobre } \\
\text { España }\end{array}$ & $45^{\prime}$ & $\begin{array}{l}\text { Prod.: SIA } \\
\text { Dir.: Louis Frank }\end{array}$ & $\begin{array}{l}\text { Filmoteca } \\
\text { Española }\end{array}$ & Documental & Anarquista \\
\hline 1937 & $\begin{array}{l}\text { Aurora de } \\
\text { Esperanza }\end{array}$ & $60^{\prime}$ & $\begin{array}{l}\text { Prod.: SIE Films } \\
\text { Dir.: Antonio Sau }\end{array}$ & $\begin{array}{l}\text { Filmoteca } \\
\text { Española }\end{array}$ & $\begin{array}{l}\text { Documental- } \\
\text { Ficción }\end{array}$ & Anarquista \\
\hline
\end{tabular}




\begin{tabular}{|c|c|c|c|c|c|c|}
\hline Fecha & Título & $\begin{array}{l}\text { Dura- } \\
\text { ción }\end{array}$ & Créditos & Filmoteca & Tipología & Ideología $^{2}$ \\
\hline 1938 & $\begin{array}{l}\text { Noticiario } \\
\text { Español N.1 }\end{array}$ & $11^{\prime}$ & $\begin{array}{l}\text { Prod.: Departamento } \\
\text { Nacional de } \\
\text { Cinematografía } \\
\text { Dir.: Manuel Augusto } \\
\text { García Viñolas }\end{array}$ & $\begin{array}{l}\text { Filmoteca } \\
\text { Española }\end{array}$ & $\begin{array}{l}\text { Documental - } \\
\text { noticiario }\end{array}$ & Franquista \\
\hline 1938 & $\begin{array}{l}\text { Noticiario } \\
\text { Español N.2 }\end{array}$ & $11^{\prime}$ & $\begin{array}{l}\text { Prod.: Departamento } \\
\text { Nacional de } \\
\text { Cinematografía } \\
\text { Dir.: Manuel Augusto } \\
\text { García Viñolas }\end{array}$ & $\begin{array}{l}\text { Filmoteca } \\
\text { Española }\end{array}$ & $\begin{array}{l}\text { Documental - } \\
\text { noticiario }\end{array}$ & Franquista \\
\hline 1938 & $\begin{array}{l}\text { Noticiario } \\
\text { Español N.3 }\end{array}$ & $11^{\prime}$ & $\begin{array}{l}\text { Prod.: Departamento } \\
\text { Nacional de } \\
\text { Cinematografía } \\
\text { Dir.: Manuel Augusto } \\
\text { García Viñolas }\end{array}$ & $\begin{array}{l}\text { Filmoteca } \\
\text { Española }\end{array}$ & $\begin{array}{l}\text { Documental - } \\
\text { noticiario }\end{array}$ & Franquista \\
\hline 1938 & $\begin{array}{l}\text { Noticiario } \\
\text { Español N.4 }\end{array}$ & $11^{\prime}$ & $\begin{array}{l}\text { Prod.: Departamento } \\
\text { Nacional de } \\
\text { Cinematografía } \\
\text { Dir.: Manuel Augusto } \\
\text { García Viñolas }\end{array}$ & $\begin{array}{l}\text { Filmoteca } \\
\text { Española }\end{array}$ & $\begin{array}{l}\text { Documental - } \\
\text { noticiario }\end{array}$ & Franquista \\
\hline 1938 & $\begin{array}{l}\text { Noticiario } \\
\text { Español N.5 }\end{array}$ & $11^{\prime}$ & $\begin{array}{l}\text { Prod.: Departamento } \\
\text { Nacional de } \\
\text { Cinematografía } \\
\text { Dir:: Manuel Augusto } \\
\text { García Viñolas } \\
\end{array}$ & $\begin{array}{l}\text { Filmoteca } \\
\text { Española }\end{array}$ & $\begin{array}{l}\text { Documental - } \\
\text { noticiario }\end{array}$ & Franquista \\
\hline 1938 & $\begin{array}{l}\text { Noticiario } \\
\text { Español N.6 }\end{array}$ & $16^{\prime}$ & $\begin{array}{l}\text { Prod.: Departamento } \\
\text { Nacional de } \\
\text { Cinematografía } \\
\text { Dir.: Manuel Augusto } \\
\text { García Viñolas }\end{array}$ & $\begin{array}{l}\text { Filmoteca } \\
\text { Española }\end{array}$ & $\begin{array}{l}\text { Documental - } \\
\text { noticiario }\end{array}$ & Franquista \\
\hline 1938 & $\begin{array}{l}\text { Noticiario } \\
\text { Español N.7 }\end{array}$ & $12^{\prime}$ & $\begin{array}{l}\text { Prod.: Departamento } \\
\text { Nacional de } \\
\text { Cinematografía } \\
\text { Dir.: Manuel Augusto } \\
\text { García Viñolas }\end{array}$ & $\begin{array}{l}\text { Filmoteca } \\
\text { Española }\end{array}$ & $\begin{array}{l}\text { Documental - } \\
\text { noticiario }\end{array}$ & Franquista \\
\hline 1938 & $\begin{array}{l}\text { [Primera } \\
\text { demostración } \\
\text { Nacional de } \\
\text { Organizaciones } \\
\text { Juveniles en } \\
\text { Sevilla] }\end{array}$ & $23^{\prime}$ & $\begin{array}{l}\text { Prod.: - } \\
\text { Dir.: - }\end{array}$ & $\begin{array}{l}\text { Filmoteca } \\
\text { Española }\end{array}$ & Documental & Franquista \\
\hline
\end{tabular}




\begin{tabular}{|c|c|c|c|c|c|c|}
\hline Fecha & Título & $\begin{array}{l}\text { Dura- } \\
\text { ción }\end{array}$ & Créditos & Filmoteca & Tipología & Ideología ${ }^{2}$ \\
\hline 1938 & $\begin{array}{l}\text { Los trece } \\
\text { puntos de la } \\
\text { victoria }\end{array}$ & - & $\begin{array}{l}\text { Prod.: Cinema Español de } \\
\text { la Subsecretaría de } \\
\text { Propaganda } \\
\text { Dir.: - }\end{array}$ & $\begin{array}{l}\text { Filmoteca } \\
\text { Española }\end{array}$ & Documental & $\begin{array}{l}\text { Gubernamental- } \\
\text { republicana }\end{array}$ \\
\hline 1938 & $\begin{array}{l}\text { España al día: } \\
\text { XXI aniversario } \\
\text { de la URSS }\end{array}$ & - & $\begin{array}{l}\text { Prod.: Film Popular - } \\
\text { Laya Films } \\
\text { Dir.: - }\end{array}$ & $\begin{array}{l}\text { Filmoteca } \\
\text { Española }\end{array}$ & $\begin{array}{l}\text { Documental - } \\
\text { noticiario }\end{array}$ & $\begin{array}{l}\text { Gubernamental- } \\
\text { republicana }\end{array}$ \\
\hline 1938 & $\begin{array}{l}\text { España al día: } \\
\text { mujeres } \\
\text { antifascistas }\end{array}$ & - & $\begin{array}{l}\text { Prod.: Film Popular - } \\
\text { Laya Films } \\
\text { Dir.: - }\end{array}$ & $\begin{array}{l}\text { Filmoteca } \\
\text { Española }\end{array}$ & $\begin{array}{l}\text { Documental - } \\
\text { noticiario }\end{array}$ & $\begin{array}{l}\text { Gubernamental- } \\
\text { republicana }\end{array}$ \\
\hline 1938 & $\begin{array}{l}\text { España al día } \\
\text { (Día de la UGT) }\end{array}$ & - & $\begin{array}{l}\text { Prod.: Film Popular - } \\
\text { Laya Films } \\
\text { Dir.: - }\end{array}$ & $\begin{array}{l}\text { Filmoteca } \\
\text { Española }\end{array}$ & $\begin{array}{l}\text { Documental - } \\
\text { noticiario }\end{array}$ & $\begin{array}{l}\text { Gubernamental- } \\
\text { republicana }\end{array}$ \\
\hline 1938 & $\begin{array}{l}\text { España al día: } \\
\text { Amigos de } \\
\text { España. El } \\
\text { cónsul de } \\
\text { Méjico en } \\
\text { España }\end{array}$ & - & $\begin{array}{l}\text { Prod.: Film Popular - } \\
\text { Laya Films } \\
\text { Dir.: - }\end{array}$ & $\begin{array}{l}\text { Filmoteca } \\
\text { Española }\end{array}$ & $\begin{array}{l}\text { Documental - } \\
\text { noticiario }\end{array}$ & $\begin{array}{l}\text { Gubernamental- } \\
\text { republicana }\end{array}$ \\
\hline 1938 & $\begin{array}{l}\text { Por todo el } \\
\text { mundo. N.15 }\end{array}$ & - & $\begin{array}{l}\text { Prod.: España al día - } \\
\text { Film Popular } \\
\text { Dir.: - }\end{array}$ & $\begin{array}{l}\text { Filmoteca } \\
\text { Española }\end{array}$ & Documental & $\begin{array}{l}\text { Gubernamental- } \\
\text { republicana }\end{array}$ \\
\hline 1938 & $\begin{array}{l}\text { La Republica } \\
\text { protege a sus } \\
\text { niños }\end{array}$ & $11^{\prime}$ & $\begin{array}{l}\text { Prod.: Ministerio de } \\
\text { Instrucción Pública y } \\
\text { Sanidad } \\
\text { Dir:: - }\end{array}$ & $\begin{array}{l}\text { Filmoteca } \\
\text { Española }\end{array}$ & Documental & $\begin{array}{l}\text { Gubernamental- } \\
\text { republicana }\end{array}$ \\
\hline 1938 & $\begin{array}{l}\text { Sunshine in } \\
\text { shadow }\end{array}$ & $11^{\prime}$ & $\begin{array}{l}\text { Prod.: Film Popular - } \\
\text { Ministerio de Instrucción } \\
\text { Pública } \\
\text { Dir:: Jean Lordier }\end{array}$ & $\begin{array}{l}\text { Filmoteca } \\
\text { Española }\end{array}$ & Documental & $\begin{array}{l}\text { Gubernamental- } \\
\text { republicana }\end{array}$ \\
\hline 1938 & $\begin{array}{l}\text { Refugees in } \\
\text { Catalonia } \\
\text { (Refugiados de } \\
\text { Guerra) } \\
\end{array}$ & $10^{\prime} 24 "$ & $\begin{array}{l}\text { Prod.: Laya Films } \\
\text { Dir.: - }\end{array}$ & $\begin{array}{l}\text { Filmoteca } \\
\text { de } \\
\text { Catalunya }\end{array}$ & Documental & $\begin{array}{l}\text { Gubernamental- } \\
\text { republicana }\end{array}$ \\
\hline 1938 & $\begin{array}{l}\text { [Visita granja- } \\
\text { escuela / } \\
\text { Dolores Rivas] }\end{array}$ & - & $\begin{array}{l}\text { Prod.: - } \\
\text { Dir.: - }\end{array}$ & $\begin{array}{l}\text { Filmoteca } \\
\text { Española }\end{array}$ & Documental & $\begin{array}{l}\text { Gubernamental- } \\
\text { republicana }\end{array}$ \\
\hline
\end{tabular}




\begin{tabular}{|c|l|c|l|l|l|l|}
\hline Fecha & \multicolumn{1}{|c|}{ Título } & $\begin{array}{c}\text { Dura- } \\
\text { ción }\end{array}$ & \multicolumn{1}{|c|}{ Créditos } & Filmoteca & \multicolumn{1}{c|}{ Tipología } & \multicolumn{1}{|c|}{ Ideología $^{2}$} \\
\hline 1939 & $\begin{array}{l}\text { Noticiario } \\
\text { Español N.28 }\end{array}$ & $13^{\prime}$ & $\begin{array}{l}\text { Prod.: Departamento } \\
\text { Nacional de } \\
\text { Cinematografía } \\
\text { Dir.: Manuel Augusto } \\
\text { García Viñolas }\end{array}$ & $\begin{array}{l}\text { Filmoteca } \\
\text { Española }\end{array}$ & $\begin{array}{l}\text { Documental - } \\
\text { noticiario }\end{array}$ & Franquista \\
\hline 1939 & $\begin{array}{l}\text { Noticiario } \\
\text { Español N.29 }\end{array}$ & $14^{\prime}$ & $\begin{array}{l}\text { Prod.: Departamento } \\
\text { Nacional de } \\
\text { Cinematografía } \\
\text { Dir.: Manuel Augusto } \\
\text { García Viñolas }\end{array}$ & $\begin{array}{l}\text { Filmoteca } \\
\text { Española }\end{array}$ & $\begin{array}{l}\text { Documental - } \\
\text { noticiario }\end{array}$ & Franquista \\
\hline
\end{tabular}

Documentales y noticiarios producidos en el extranjero sobre la guerra en España

\begin{tabular}{|c|l|l|l|l|l|}
\hline Fecha & \multicolumn{1}{|c|}{ Título } & Duración & \multicolumn{1}{c|}{ Créditos } & \multicolumn{1}{|c|}{ Filmoteca } & Tipología \\
\hline 1936 & Ispanija & $8^{\prime} 52^{\prime \prime}$ & $\begin{array}{l}\text { Prod.: Soiuzkinochronica } \\
\text { Dir: Karmen Roman - } \\
\text { Boris Makaseiev }\end{array}$ & $\begin{array}{l}\text { Filmoteca de } \\
\text { Valencia }\end{array}$ & Documental \\
\hline 1936 & $\begin{array}{l}\text { Na pomosch dietiam i } \\
\text { zhenschinam } \\
\text { gueroicheskoi Ipanii } \\
\text { (En ayuda de los } \\
\text { niños y mujeres de la } \\
\text { heroica España) }\end{array}$ & $\begin{array}{l}\text { Prod.: Soiuzkinochronica } \\
\text { Dir.: L. Zernov }\end{array}$ & $\begin{array}{l}\text { Filmoteca } \\
\text { Española }\end{array}$ & Documental \\
\hline 1937 & $\begin{array}{l}\text { Novie Tovarischi } \\
\text { (Nuevos amigos) }\end{array}$ & - & $\begin{array}{l}\text { Prod.: Estudio Central de } \\
\text { Documentales de Moscú }\end{array}$ & $\begin{array}{l}\text { Filmoteca } \\
\text { Española }\end{array}$ & Documental \\
\hline 1937 & $\begin{array}{l}\text { Ispanskie dieti V } \\
\text { SSSR (Niños } \\
\text { españoles en la URSS) }\end{array}$ & $330^{\prime}$ & $\begin{array}{l}\text { Prod.: Soiuzkinochronica } \\
\text { Dir.: R. Guikov }\end{array}$ & $\begin{array}{l}\text { Filmoteca } \\
\text { Española }\end{array}$ & Documental \\
\hline 1937 & $\begin{array}{l}\text { K Sobytijam v Ispanii } \\
\text { N. 20 (Sobre los } \\
\text { sucesos de España) }\end{array}$ & $22^{\prime}$ & $\begin{array}{l}\text { Prod.: Soiuzkinochronica } \\
\text { Dir:: N. Karamzinsky; V. } \\
\text { Erofieff }\end{array}$ & $\begin{array}{l}\text { Filmoteca } \\
\text { Española }\end{array}$ & Documental \\
\hline 1937 & $\begin{array}{l}\text { Modern Orphans of } \\
\text { Storm }\end{array}$ & - & $\begin{array}{l}\text { Prod.: Victor Saville } \\
\text { Productions; Realist } \\
\text { Films; National Joint } \\
\text { Committee for Spanish } \\
\text { Relief } \\
\text { Dir:: }-\end{array}$ & $\begin{array}{l}\text { Filmoteca } \\
\text { Española }\end{array}$ & Documental \\
\hline 1937 & $\begin{array}{l}\text { Prod.: Progressive Film } \\
\text { Dir.: Herbert Marshall }\end{array}$ & $\begin{array}{l}\text { Filmoteca } \\
\text { Española }\end{array}$ & Documental \\
\hline
\end{tabular}




\begin{tabular}{|c|c|c|c|c|c|}
\hline Fecha & Título & Duración & Créditos & Filmoteca & Tipología \\
\hline 1937 & Heart of Spain & $30^{\prime}$ & $\begin{array}{l}\text { Prod.: Frontier Film - } \\
\text { American Bureau to Aid } \\
\text { Spanish Democracy - } \\
\text { Canadian Committee to } \\
\text { Aid Spain } \\
\text { Dir.: Herbert Kline - } \\
\text { Geza Karpathi }\end{array}$ & $\begin{array}{l}\text { Filmoteca } \\
\text { Española }\end{array}$ & Documental \\
\hline 1938 & $\begin{array}{l}\text { Dobro Poxhalovath } \\
\text { (Sed Bienvenidos) }\end{array}$ & $11^{\prime}$ & $\begin{array}{l}\text { Prod.: Soiuzkinochronica } \\
\text { Dir:: Vasili Soloviov }\end{array}$ & $\begin{array}{l}\text { Filmoteca } \\
\text { Española }\end{array}$ & Documental \\
\hline 1938 & S. O. S. Espagne & - & $\begin{array}{l}\text { Prod.: Societe de } \\
\text { Porductions La } \\
\text { Marseillaise } \\
\text { Dir.: Jean Lordier } \\
\end{array}$ & $\begin{array}{l}\text { Filmoteca } \\
\text { Española }\end{array}$ & Documental \\
\hline 1938 & L'Espagne vivra & $43^{\prime}$ & $\begin{array}{l}\text { Prod.: Films Populaires } \\
\text { Dir:: Henri Cartier- } \\
\text { Bresson } \\
\end{array}$ & $\begin{array}{l}\text { Filmoteca } \\
\text { Española }\end{array}$ & Documental \\
\hline 1938 & $\begin{array}{l}\text { Behind the Spanish } \\
\text { lines }\end{array}$ & $20^{\prime}$ & $\begin{array}{l}\text { Prod.: Progressive Film } \\
\text { Institute } \\
\text { Dir:: Sidney Cole. } \\
\text { Thorold Dickinson } \\
\end{array}$ & $\begin{array}{l}\text { Filmoteca } \\
\text { Española }\end{array}$ & Documental \\
\hline 1938 & Spanish ABC & $19^{\prime}$ & $\begin{array}{l}\text { Prod.: Progressive Film } \\
\text { Institute } \\
\text { Dir:: Sidney Cole. } \\
\text { Thorold Dickinson } \\
\end{array}$ & $\begin{array}{l}\text { Filmoteca } \\
\text { Española }\end{array}$ & Documental \\
\hline 1938 & Return to life & $43^{\prime}$ & $\begin{array}{l}\text { Prod.: Frontier Films - } \\
\text { Medical Bureau the } \\
\text { North American ASD } \\
\text { Dir:: Henri Cartier- } \\
\text { Bresson - Herbert Kline }\end{array}$ & $\begin{array}{l}\text { Filmoteca } \\
\text { Española }\end{array}$ & Documental \\
\hline
\end{tabular}

Este lugar que ocupa la infancia en el conjunto de producciones cinematográficas documentales podemos interpretarlo como una preocupación explícita por la vida cotidiana de estos niños y niñas, pero también como indicativo del «uso propagandístico» de la infancia. Filmados en ámbitos escolares, en colonias-refugio, participando de espectáculos gimnástico-artísticos o en desfiles políticos y militares, la población infantil aparece como icono de los ideales de ciudadanía promovidos por los republicanos, por los anarquistas, por los comunistas y por los franquistas.

Vemos en ello una clara manifestación estética que vehicula la protección y la proyección de la infancia en función de unos cánones imaginarios sobre su actualidad, pero también el posible devenir de la población. 
Visualizar los contenidos estéticos manifestados en estos «textos» nos brinda, pues, la oportunidad de acercarnos tanto a la filosofía política de los grupos en conflicto como a sus estructuras de lo imaginario.

Precisamente proponemos a continuación una comparativa entre cuatro producciones que dedican la atención a la educación estética de los niños y niñas como parte de una educación ideológica, moral, corporal o integral, que se lleva a cabo a través de la actividad lúdica, deportiva y artística en ambientes escolares, de colonias y en manifestaciones públicas.

Hay que añadir también que hemos seleccionado estos filmes de entre todos los posibles, porque en los mismos claramente se observan los aspectos indicados de proyección política a través de la acción estética, seleccionando únicamente noticiarios o documentales que incorporaban voz por cuanto nuestra intención era aquí focalizar la atención en la oralidad.

\section{Ficha técnica}

\begin{tabular}{|c|c|c|c|c|}
\hline Ideología & Producción & Ficha técnica & Secuenciación & Observaciones \\
\hline Franquista & $\begin{array}{l}\text { Noticiario } \\
\text { Español N. 3, } \\
1938\end{array}$ & $\begin{array}{l}\text { Prod.: } \\
\text { Departamento } \\
\text { Nacional de } \\
\text { Cinematografía } \\
\text { Duración: 3' }\end{array}$ & $\begin{array}{l}\text { Créditos de inicio y } 3 \\
\text { actos: } \\
\text { (1) Situación de la } \\
\text { población en refugios. } \\
\text { (2) Actividad de los } \\
\text { oponentes en los } \\
\text { «pueblos ocupados». } \\
\text { (3) Actividad del Auxilio } \\
\text { Social. }\end{array}$ & $\begin{array}{l}\text { Acceso y visionado } \\
\text { en Filmoteca } \\
\text { Española }\end{array}$ \\
\hline Comunista & $\begin{array}{l}\text { Un periódico } \\
\text { mural, } 1937\end{array}$ & $\begin{array}{l}\text { Prod.: Ediciones } \\
\text { Antifascistas Films } \\
\text { Dir:: Manuel } \\
\text { Ordóñez } \\
\text { Operador: Ovidio } \\
\text { Condre } \\
\text { Duración: 6’30" }\end{array}$ & $\begin{array}{l}\text { Créditos de inicio y final } \\
\text { y } 3 \text { actos: } \\
\text { (1) Introducción con } \\
\text { aproximación a la } \\
\text { realidad social } \\
\text { contrastada con la } \\
\text { realidad de la escuela. } \\
\text { (2) Desarrollo de la } \\
\text { actividad de producción } \\
\text { de un periódico mural. } \\
\text { (3) Conclusión de los } \\
\text { anhelos adjudicados a } \\
\text { los niños y niñas. }\end{array}$ & $\begin{array}{l}\text { Acceso online: } \\
\text { http://www.rtve.es/ } \\
\text { alacarta/ } \\
\text { videos/archivo- } \\
\text { historico/periódico- } \\
\text { mural/2833334/ }\end{array}$ \\
\hline
\end{tabular}




\begin{tabular}{|c|c|c|c|c|}
\hline Ideología & Producción & Ficha técnica & Secuenciación & Observaciones \\
\hline & & & $\begin{array}{l}\text { Se va superponiendo la } \\
\text { música y la voz } \\
\text { narrativa dando pie a } \\
\text { los diferentes saltos de } \\
\text { contenido. } \\
\text { Se recurre a la técnica } \\
\text { de anticipación temática } \\
\text { en aquellos temas } \\
\text { considerados más } \\
\text { relevantes, mediante la } \\
\text { inclusión de un objeto o } \\
\text { palabra que anticipa el } \\
\text { siguiente contenido. }\end{array}$ & \\
\hline Anarquista & $\begin{array}{l}\text { El Frente y la } \\
\text { Retaguardia, } \\
1937\end{array}$ & $\begin{array}{l}\text { Prod.: SIE } \\
\text { Dir.: Joaquín Giner } \\
\text { Duración: 29'30" } \\
\text { Fragmentos } \\
\text { educación: } 40 " \text { + } \\
\text { 2'49" }\end{array}$ & $\begin{array}{l}\text { Créditos de inicio y final } \\
\text { y } 8 \text { actos: } \\
\text { (1) Presentación de } \\
\text { ideología de guerra. } \\
\text { (2) Industria de guerra: } \\
\text { taller, fábrica, campo. } \\
\text { (3) Comunicaciones } \\
\text { entre campo y ciudad - } \\
\text { tren-. } \\
\text { (4) Escenas urbanas con } \\
\text { diferentes desfiladas. } \\
\text { (5) Campo de batalla. } \\
\text { (6) Hospital de } \\
\text { convalecencia. } \\
\text { (7) La atención a los } \\
\text { niños. } \\
\text { (8) Focalización de la } \\
\text { atención a la palabra } \\
\text { Libertad. }\end{array}$ & $\begin{array}{l}\text { Acceso y visionado } \\
\text { en Filmoteca } \\
\text { Española }\end{array}$ \\
\hline $\begin{array}{l}\text { Gubernamental } \\
\text { republicana }\end{array}$ & $\begin{array}{l}\text { Noticiario n. } 1 . \\
\text { La Revolución } \\
\text { y los niños, } \\
1937\end{array}$ & $\begin{array}{l}\text { Prod.: Laya Films } \\
\text { Duración: 1'10" }\end{array}$ & $\begin{array}{l}\text { Anuncio de tema y } \\
\text { desarrollo en una sola } \\
\text { secuencia }\end{array}$ & $\begin{array}{l}\text { Acceso y visionado } \\
\text { en Filmoteca } \\
\text { Española }\end{array}$ \\
\hline
\end{tabular}


Ambientación

\begin{tabular}{|c|c|c|}
\hline Producción & Ambientes & Principales actividades \\
\hline $\begin{array}{l}\text { Noticiario Español } \\
\text { N. 3, } 1938\end{array}$ & $\begin{array}{l}\text { Cuevas } \\
\text { Pueblo rural } \\
\text { Instituciones auxilio social }\end{array}$ & $\begin{array}{l}\left(08^{\prime} 28^{\prime \prime}\right) \text { Población que aguarda y vive en refugio } \\
\left(08^{\prime} 28^{\prime \prime}\right) \text { Destrucción de material de culto } \\
\left(09^{\prime} 19^{\prime \prime}\right) \text { Actividad de costura en terraza } \\
\left(9^{\prime 2} 28^{\prime \prime}\right) \text { Albergue niños y niñas: recreo y actividad } \\
\text { física en el jardín y en la playa. Clase en el aire } \\
\text { libre: Inspección salud. }\end{array}$ \\
\hline $\begin{array}{l}\text { Un periódico mural, } \\
1937\end{array}$ & $\begin{array}{l}\text { Escuela: aulas y patio } \\
\text { Edades del alumnado diversa } \\
\text { y coeducativa }\end{array}$ & 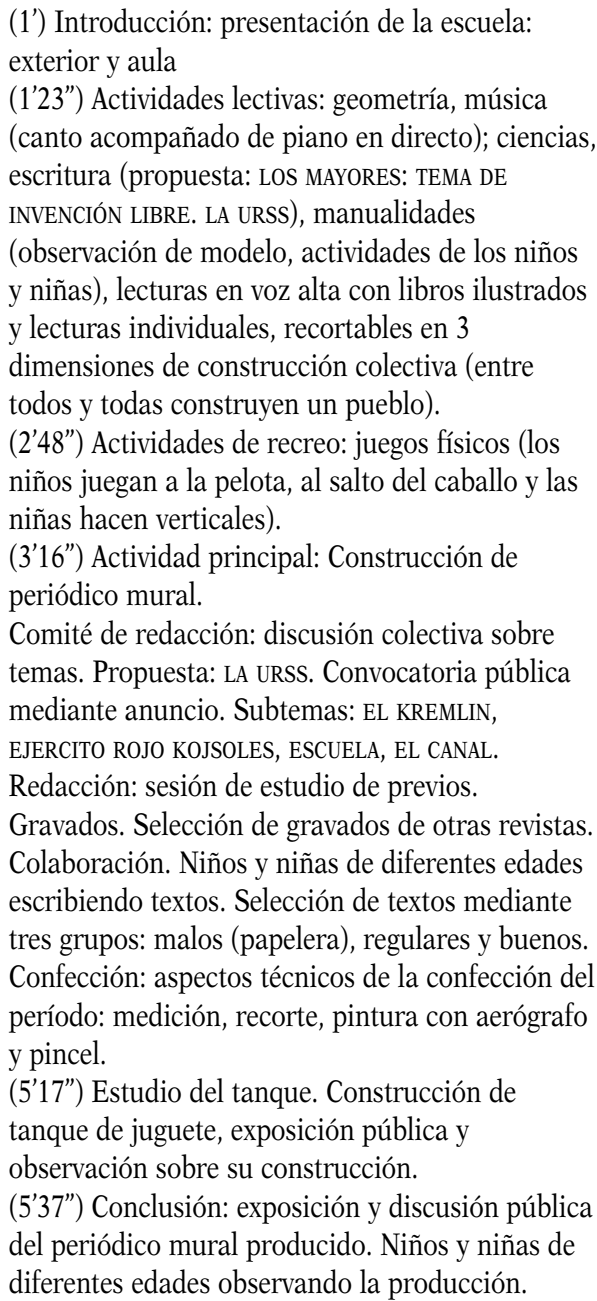 \\
\hline
\end{tabular}




\begin{tabular}{|c|c|c|}
\hline Producción & Ambientes & Principales actividades \\
\hline $\begin{array}{l}\text { El Frente y la } \\
\text { Retaguardia, } 1937\end{array}$ & $\begin{array}{l}\text { Introducción: mensaje político } \\
\text { con escenas de guerra } \\
\text { De las escenas educativas: } \\
\text { presenta un día en una } \\
\text { colonia-refugio. Dormitorios, } \\
\text { espacios de baño, comedores, } \\
\text { talleres, aulas, teatro exterior } \\
\text { espacios de recreo y exteriores }\end{array}$ & $\begin{array}{l}\text { (17'14") Introducción: presentación de la colonia- } \\
\text { refugio. Vistas exteriores. } \\
\left(17^{\prime} 37^{\prime \prime}\right) \text { El despertar en los dormitorios colectivos } \\
\text { de la colonia-refugio } \\
\left(18^{\prime} 14^{\prime \prime}\right) \text { Hábitos de higiene } \\
\left(18^{\prime} 42^{\prime \prime}\right) \text { Comedores colectivos para niños y adultos } \\
\left(19^{\prime} 17^{\prime \prime}\right) \text { Actividades de taller: forja, carpintería, } \\
\text { dibujo técnico } \\
\left(19^{\prime} 48^{\prime \prime}\right) \text { Discurso en el aula sobre la importancia } \\
\text { del teatro } \\
\left(20^{\prime} 22^{\prime \prime}\right) \text { Actividad física al aire libre. } \\
\text { Composiciones corporales grupales. }\end{array}$ \\
\hline $\begin{array}{l}\text { Noticiario n. 1. La } \\
\text { Revolución y los niños }\end{array}$ & Ciudad y escuela & $\begin{array}{l}\left(0^{\prime} 22^{\prime \prime}\right) \text { Niños y niñas hablando } \\
\left(0^{\prime} 22^{\prime \prime}\right) \text { Niños y niñas aprendiendo en clase al aire } \\
\text { libre } \\
\left(0^{\prime} 23^{\prime \prime}\right) \text { Salida de los niños y niñas a la ciudad. }\end{array}$ \\
\hline
\end{tabular}

\section{Textos orales}

\begin{tabular}{|c|c|c|}
\hline $\begin{array}{l}\text { Produc- } \\
\text { ción }\end{array}$ & $\begin{array}{l}\text { Oralidad. } \\
\text { Transcripción de fragmentos }\end{array}$ & $\begin{array}{l}\text { Observa- } \\
\text { ciones }\end{array}$ \\
\hline $\begin{array}{l}\text { Noticiario } \\
\text { Español N. 3, } \\
1938\end{array}$ & $\begin{array}{l}\text { Speech 1: } \\
\text { 1.1. 00'07" [escena de paisaje rural] } \\
\text { Como siempre la aviación roja avanza sobre pueblecitos indefensos } \\
\text { sin interés militar alguno } \\
\text { 1.2. 07'15" [escena de refugio en cueva] } \\
\text { Refugios ocupados por la población civil que ante las reiteradas } \\
\text { alarmas se ve obligada a permanecer en ellos noche y día. } \\
\text { 1.3. 07'57" [imagen grupos concretos] } \\
\text { He aquí un grupo bien simpático. Estos pequeñuelos hacen su vida en } \\
\text { los refugios sin que, como bien se ve, les quite el apetito el trágico } \\
\text { murmureo de los motores rojos. } \\
\text { Speech 2: } \\
2.1 . \quad 08 \text { '28" [ante la iglesia] } \\
\text { Estas imágenes impresionadas en el campo rojo, hablan claro y alto } \\
\text { de la clase de respeto que la iglesia merece a los milicianos al servicio } \\
\text { [ ]. } \\
\text { Como siempre y en todos los pueblos sometidos a dominación, los } \\
\text { rojos saquean las iglesias y condenan los sagrados monumentos del } \\
\text { culto a la eterna pira. } \\
\text { Speech 3: } \\
\text { 3.1. 09'19" [en una casa - institución del Auxilio Social] }\end{array}$ & $\begin{array}{l}\text { La narración con } \\
\text { música acompaña } \\
\text { las imágenes que } \\
\text { van adquiriendo } \\
\text { capacidad } \\
\text { discursiva a lo } \\
\text { largo del } \\
\text { noticiario. }\end{array}$ \\
\hline
\end{tabular}




\begin{tabular}{|c|c|c|}
\hline $\begin{array}{l}\text { Produc- } \\
\text { ción }\end{array}$ & $\begin{array}{l}\text { Oralidad. } \\
\text { Transcripción de fragmentos }\end{array}$ & $\begin{array}{l}\text { Observa- } \\
\text { ciones }\end{array}$ \\
\hline & $\begin{array}{l}\text { El Auxilio Social, una de las instituciones que honran a la nueva } \\
\text { España ha adquirido desarrollo ejemplar en menos de dos años de } \\
\text { funcionamiento. 3.2. 09'28" [en el jardín] } \\
\text { Las camaradas de otras provincias, las falangistas de Málaga, se han } \\
\text { impuesto la general y simpática tarea de llevar pan y alegría a los } \\
\text { niños de España. } \\
\text { 3.3. } 09^{\prime} 40 \text { " [en la playa] } \\
\text { 3.4. } 09^{\prime} 59^{\prime \prime} \text { [clase al aire libre] } \\
\text { 3.5. 10'01" [inspección de salud] } \\
\text { Bajo su caricia y eterna solicitud, los pequeños malagueños se sienten } \\
\text { felices y adquieren vigor físico y moral. } \\
\text { 3.6. } 10^{\prime} 10^{\prime \prime} \text { [comida en mesa en el exterior] }\end{array}$ & \\
\hline $\begin{array}{l}\text { Un periódico } \\
\text { mural, } 1937\end{array}$ & 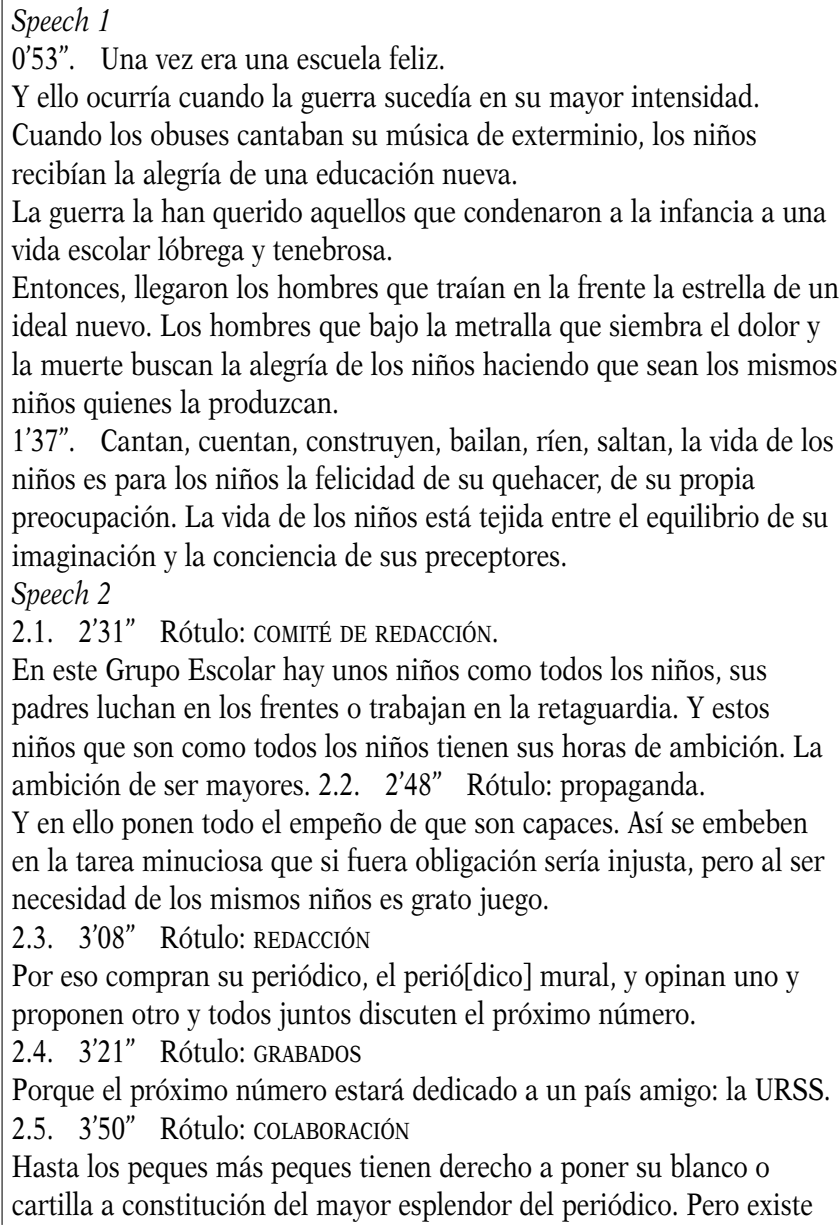 & $\begin{array}{l}\text { La narración (voz } \\
\text { infantil de niño en } \\
\text { off) va } \\
\text { acompañada de } \\
\text { música y los } \\
\text { rótulos que van } \\
\text { introduciendo las } \\
\text { diferentes escenas. }\end{array}$ \\
\hline
\end{tabular}




\begin{tabular}{|c|c|c|}
\hline $\begin{array}{l}\text { Produc- } \\
\text { ción }\end{array}$ & $\begin{array}{l}\text { Oralidad. } \\
\text { Transcripción de fragmentos }\end{array}$ & $\begin{array}{l}\text { Observa- } \\
\text { ciones }\end{array}$ \\
\hline & $\begin{array}{l}\text { un criterio y este criterio es del comité de redacción, que es quien en } \\
\text { último extremo decide sobre la publicación de los trabajos. } \\
\text { 2.6. 4'26" Rótulo: SELEcción } \\
\text { Los caminos que conducen a la pedagogía hasta su aplicación también } \\
\text { pueden ser claros y son claros tanto la luz que los alumbra es la luz de } \\
\text { la alegría infantil. } \\
\text { La aridez de la pedagogía desaparece para el niño cuando interviene } \\
\text { su voluntad. } \\
\text { 2.7. 4'44" Rótulo: conFEcción } \\
\text { Por eso trabajan con este ahínco en la que consideran obra suya, } \\
\text { nacida al calor de su pensamiento, trabajan, cortan, dibujan, pegan } \\
\text { y siempre con la ayuda del profesor que no es el maestro de seño duro } \\
\text { y de mirada sorda tan grato a la España de antes, sino que es un niño } \\
\text { más, entusiasmado sobre la obra que es suya porque es de todos los } \\
\text { niños. } \\
\text { Speech } 3 \\
3.1 . \quad 5 \text { '17" Rótulo: TANQuE } \\
\text { Los niños también quieren ganar la guerra. Sus manos desnudas y } \\
\text { débiles dan lecciones de entusiasmo a los mayores. } \\
\text { El hierro, es materia dura para sus pocos años, pero sus sueños se } \\
\text { plasman en el papel, en el cartón, en la tinta, en el color de sus } \\
\text { lapiceros. } \\
\text { 3.2. 5’37" Rótulo: EL PERIóDico muRAL } \\
\text { Así se sucede en este cuento real, en este tiempo en que los obuses } \\
\text { cantan su música de exterminio. }\end{array}$ & \\
\hline $\begin{array}{l}\text { El Frente y la } \\
\text { Retaguardia, } \\
1937\end{array}$ & $\begin{array}{l}\text { Parte } 1 \\
\text { Speech } 1 \\
\text { 1.1. 1'04" [A través de rótulos] } \\
\text { Combates sin precedentes. } \\
\text { Hechos de insospechado heroísmo. } \\
\text { Sacrificios sublimes } \\
\text { Valor } \\
\text { Coraje } \\
\text { Esta es la Guerra } \\
\text { La Lucha cruenta } \\
\text { Que ha de redimir a la Humanidad } \\
\text { Todos sin distinción } \\
\text { Sin cobardes emboscamientos } \\
\text { Todos a trabajar para } \\
\text { ¡!La Guerra!! } \\
\text { [...] } \\
\text { Speech } 2 \\
\text { 2.1. 17'14" [Escena exterior jardines hospital militar] } \\
\text { Son mis hijos. }\end{array}$ & $\begin{array}{l}\text { La narración se } \\
\text { constituye de } \\
\text { pequeños diálogos. }\end{array}$ \\
\hline
\end{tabular}




\begin{tabular}{|c|c|c|}
\hline $\begin{array}{l}\text { Produc- } \\
\text { ción }\end{array}$ & $\begin{array}{c}\text { Oralidad. } \\
\text { Transcripción de fragmentos }\end{array}$ & $\begin{array}{c}\text { Observa- } \\
\text { ciones }\end{array}$ \\
\hline & 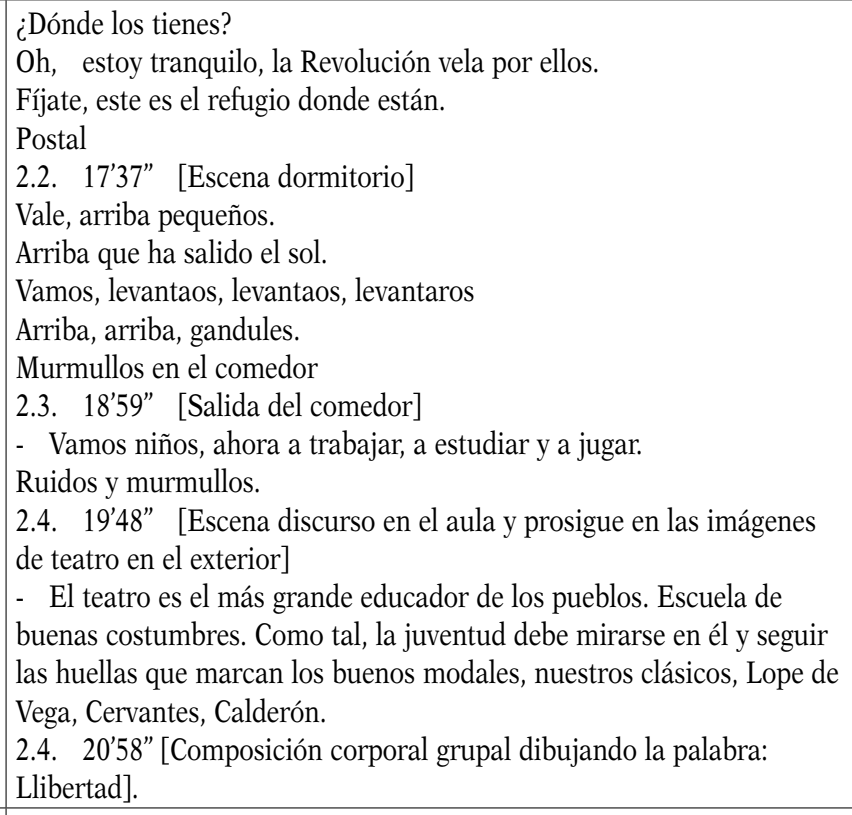 & \\
\hline $\begin{array}{l}\text { Noticiario } \\
n .1 \text {. La } \\
\text { Revolución y } \\
\text { los niños }\end{array}$ & $\begin{array}{l}1.100 \text { '22" [Primeros planos de niños y niñas]. } \\
\text { En Cataluña y en España se siente una especial ternura por los niños. } \\
\text { En plena guerra, en plena transformación social, el niño sigue siendo } \\
\text { el tema principal de la actualidad política. } \\
1.2000^{\prime} 42 \text { " [Clase al aire libre en la Escuela del Mar] } \\
\text { Escuela libre. } \\
\text { Sentido crítico acusado por una generación nueva que se forma en la } \\
\text { alegría. } \\
1.301^{\prime 2} 23 " \text { [Salida de los niños y niñas a la ciudad]. }\end{array}$ & $\begin{array}{l}\text { La narración } \\
\text { discursiva va } \\
\text { acompañada de } \\
\text { imágenes que } \\
\text { refuerzan el } \\
\text { discurso. }\end{array}$ \\
\hline
\end{tabular}

\section{Textos visuales}

\begin{tabular}{|l|l|}
\hline \multicolumn{1}{|c|}{ Producción } & \multicolumn{1}{c|}{ Secuencia de imágenes } \\
\hline Noticiario Español & $\begin{array}{l}\text { El discurso a través de la imagen está construido en tres } \\
\text { momentos: un primero de planos panorámicos y de aproximación } \\
\text { a grupos de visualidad dura, un segundo de acción, y en el tercer } \\
\text { momento las imágenes se vuelven más detallistas, con más } \\
\text { fragmentos grupales que individuales. La mayoría de las imágenes } \\
\text { del segundo y tercer momento son de acción. }\end{array}$ \\
\hline
\end{tabular}




\begin{tabular}{|c|c|}
\hline Producción & Secuencia de imágenes \\
\hline $\begin{array}{l}\text { Un periódico } \\
\text { mural, } 1937\end{array}$ & $\begin{array}{l}\text { Las imágenes más frecuentes son figurativas. En ellas aparecen } \\
\text { sobre todo niños y niñas. Las imágenes iconográficas son } \\
\text { fundamentalmente las que acompañan los rótulos. Se presentan } \\
\text { composiciones artísticas realizadas mediante collage de } \\
\text { periódicos. } \\
\text { Aunque numéricamente hay una mayor presencia de imágenes } \\
\text { de colectivos, las imágenes que se centran en individuos } \\
\text { concretos resaltan en el conjunto de la composición. } \\
\text { A lo largo del filme observamos dos tipos de planos: los planos } \\
\text { directos que mediante un fotograma o un tráiler representan en } \\
\text { su mayoría acciones, y los planos fijos que dan pie a la propuesta } \\
\text { de tema o nos enseñan los resultados de las acciones. } \\
\text { Por otra parte destaca la combinación equilibrada entre planos } \\
\text { generales, planos de proximidad y planos de detalle. Los planos } \\
\text { generales representan el ambiente y la colectividad (aula, } \\
\text { recreo...). } \\
\text { Los planos de proximidad muestran acciones (grupos de } \\
\text { discusión, procesos, etc.). } \\
\text { Los planos de detalle se centran en los resultados, en los } \\
\text { materiales y en aspectos específicos de la técnica. }\end{array}$ \\
\hline $\begin{array}{l}\text { El Frente y la } \\
\text { Retaguardia, } 1937\end{array}$ & $\begin{array}{l}\text { En el documental se suceden las imágenes de acción. En la } \\
\text { primera parte (el discurso político-ideológico) tienen más relieve } \\
\text { los rótulos que las imágenes que los acompañan. Por el } \\
\text { contrario, en el fragmento dedicado a la educación, las imágenes } \\
\text { cobran más fuerza. La narración oral complementa el discurso } \\
\text { visual. } \\
\text { Los planos son fundamentalmente generales y representan la } \\
\text { colectividad. }\end{array}$ \\
\hline $\begin{array}{l}\text { Noticiario n. } 1 . \text { La } \\
\text { Revolución y los } \\
\text { niños }\end{array}$ & $\begin{array}{l}\text { El documental empieza con primeros planos de detalle, le } \\
\text { prosiguen los planos medios grupales, para finalmente ofrecer } \\
\text { una visión panorámica. }\end{array}$ \\
\hline
\end{tabular}

Como podemos observar, los filmes y documentales presentados en este trabajo contienen claras diferencias en la representación y evocación de las ideas que querían transmitir a pesar de tener unos presupuestos formales y materiales comunes. Sobre las ideas educativas, en unas destacan la confrontación, en otras, aunque esta aparece como fondo, se centra en los aspectos inherentes a los discursos ideológicos. En la primera película, los adultos aparecen como protagonistas; en las otras, como acompañantes. Todas las acciones educativas que hacen los niños y niñas en la primera son de repetición. En la segunda, son acciones sugeridas e imaginadas. En la tercera y en la cuarta, mezclan acciones de 
repetición, de recepción y de decisión. Y en todas se muestra el presente y se apunta al porvenir de los niños y niñas. Como se ve, las semejanzas y las diferencias están en los detalles.

Esta es la razón principal por la cual queremos señalar que el modelo de análisis presentado es un texto de apertura para pensar, imaginar e indagar las opciones estético-ideológicas que se conformaron durante la Guerra Civil Española.

\section{Nota sobre los autores:}

Eulàlia Collelldemont es profesora de la Facultad de Educación de la Universidad de Vic - Universidad Central de Cataluña, especializada en el área de historia de la educación, educación estética y patrimonio educativo. Actualmente dirige el MUVIP (Museo Virtual de Pedagogía de la Universidad de Vic). Ha dirigido los siguientes proyectos financiados: Collelldemont, E. (PI1) y Casanovas, J. (PI2): RADAE. Revisión y análisis documentales propagandísticos y anuncios audiovisuales educativos producidos entre 1914-1939 en España. Ministerio de Educación y competitividad. Programa Estatal de I+D+I orientada a los Retos de la Sociedad. 2014-2016. (Ref.: EDU201348067-R) y Collelldemont, E., (PI): DiDD. Documentación y difusión digital del patrimonio educativo producido entre 1936-1939 en las escuelas de Barcelona. Los dibujos de la infancia sobre la vida cotidiana en tiempos de guerra. Plan Nacional de I+D+I 2011-2013. (Ref.: EDU2010-20280). Participa en el proyecto Pensament pedagògic $i$ discursos educatius en la construcció europea cent anys després de la Gran Guerra. Entre el passat i el futur. Recercaixa (2015ACUP 00073). Publicaciones: coordinación del monográfico "Children, education and politics in everyday life: children education and politics at a time of conflict - the Spanish Civil War (1936-1939)», Paedagogica Historica, 54 (1), (2015); «Tracing the evolution of education through street maps and town plans: educational institutions in the maps of Edinburgh during the seventeenth, eighteenth and nineteenth centuries», Paedagogica Historica, 50 (5), (2014): 651-667; (editora) Investigar la història de l'educació amb imatges. (Vic: EUMO, 2014); «La memoria visual de la escuela», Educatio XXI, 28 (2), (2012):133-156. 
Josep Casanovas Prat es profesor y vicedecano de la Facultad de Educación de la Universidad de Vic - Universidad Central de Cataluña. Sus principales líneas de investigación están centradas en la historia de la Guerra Civil Española y sobre la historia de la educación física. Codirige el proyecto de investigación Collelldemont, E. (PI1), Casanovas, J. (PI2): RADAE. Revisión y análisis documentales propagandísticos y anuncios audiovisuales educativos producidos entre 1914-1939 en España. Ministerio de Educación y competitividad. Programa Estatal de I+D+I orientada a los Retos de la Sociedad. 2014-2016. (Ref.: EDU201348067-R). Participó como investigador en el proyecto DiDD. Documentación y difusión digital del patrimonio educativo producido entre 1936-1939 en las escuelas de Barcelona. Los dibujos de la infancia sobre la vida cotidiana en tiempos de guerra. Plan Nacional de I+D+I 2011-2013. (Ref.: EDU2010-20280). Entre sus publicaciones destaca: Padrós Tuneu, N.; Carrillo Flores, I.; Casanovas Prat, J.; Prat Viñolas, P.; Tort Bardolet, A. y Gómez Mundó, A. «The Spanish Civil War as seen through children's drawings of the time», Paedagogica Historica, 51 (2015): 478-495; Casanovas Prat, Josep; Padrós Tuneu, Núria i Prat Viñolas, Pilar. «La historia de la educación a través de los documentales educativos: el uso de filmes propagandísticos en el primer tercio del siglo XX», en Actas del XVIII Coloquio de Historia de la Educación: arte, literatura y educación: Vic, 8, 9 y 10 de julio de 2015, eds. Padrós, Núria, Collelldemont, Eulàlia, Soler, Joan (Vic. Servei de Publicacions de la Universitat de Vic - Universitat Central de Catalunya, 2015): 311-319; «L'experiència de la guerra a través dels dibuixos», en Investigar la història de l'educació amb imatges, eds., Casanovas i Prat, Josep y Collelldemont Pujadas, Eulàlia (Barcelona: Eumogràfic-MUVIP, 2014); Casanovas Prat, Josep y Tort Bardolet, Antoni. «Els infants i la guerra. Consideracions al voltant d'una investigació sobre dibuixos d'escolars durant la Guerra Civil espanyola». Temps d'Educació, (2013): p. 63-76; "Catalunya i els jocs olímpics», en L'Esport a Catalunya, ed. Santacana, Carles (Barcelona: Fundació Lluís Carulla, 2008): 45-57. 